\title{
Older women, health, and social care in Singapore
}

\author{
Treena Wu • Angelique Chan
}

Published online: 26 January 2011

(C) The Author(s) 2011. This article is published with open access at Springerlink.com

\begin{abstract}
A key demographic feature in the high-income country of Singapore is that women have longer years of life than men, and the aging pattern in Singapore is similar to that of Northern Europe. This paper describes how this current generation of older Singaporean women aged 65 and above experiences declines in health status and well-being as they age. Their vulnerability is the higher risk of chronic illnesses stemming from longer life expectancy and a lower likelihood of access to appropriate health and social care. This is because health and social care in old age are mainly financed by individual out-of-pocket spending which includes support from adult children. Unlike Northern Europe, Singapore does not yet have a well-developed social welfare system to support women in old age.
\end{abstract}

\section{Introduction}

A central feature of mortality trends in developed countries in the twentieth century is the widening sex differentials in life expectancy (Kinsella and Velkoff 2001). In 1900 , in Europe, women typically outlived men by 2 or 3 years. Today, in Northern Europe, the average gap between the sexes is approximately 7 years, with female life expectancy exceeding 80 years and male life expectancy exceeding 74 years.

It is not surprising that there is a tendency for the growth of older male and female populations to be associated with the countries of Europe. What is less known is that the absolute numbers of the elderly in Singapore are large and increasing. After the country achieved independence in 1965, there were over 47,200 individuals aged 65 and above. ${ }^{1}$ In just 45 years, this number increased to $338,387 .{ }^{2}$ Likewise in terms

\footnotetext{
${ }^{1}$ Ministry of Community Development, Youth and Sports 2008/2009, computations

${ }^{2}$ Statistics Singapore, National Population Census 2010

T. Wu $(\bowtie) \cdot$ A. Chan

Health Services and Systems Research Program, Duke - National University of Singapore (NUS)

Graduate Medical School, 8 College Road, Singapore 169857, Singapore

e-mail: soctwsl@nus.edu.sg
} 
of the sex differentials, female life expectancy in Singapore is nearly 84 years and exceeds male life expectancy by nearly 5 years. While longer life amongst women in Singapore is a human success story, this current generation of older women aged 65 and above experiences declines in health status and well being as they age (Metha 2002). Their vulnerability is the higher risk of chronic illnesses as they live longer with a lower likelihood of access to appropriate health and social care which represents out-of-pocket expenses. This stems from their less opportunity for formal sector employment with social security benefits, limited social welfare, none or little formal education, and fewer children to depend on for income, support, and care.

This paper aims to describe this current generation of older women aged 65 and above in Singapore and the challenges they face in receiving health and social support. This considers how social security, health care, and social care are financed and provided.

\section{Life expectancy trends}

The life expectancy trend in Singapore follows that in Northern Europe and diverges from other countries in Southeast Asia. The focus is placed on Northern Europe instead of all of Europe. This is due to the fact that the Singapore social security financing and provision were initially developed when it was a British colony and that the UK is classified by the United Nations as a part of Northern Europe (Department of Economic and Social Affairs of the United Nations Secretariat 2009). Figure 1 shows the comparison of trends in life expectancy at birth, 19652010 in Singapore, Southeast Asia, and Northern Europe.

From 1965, when Singapore achieved independence, until 2010, the figure shows that the trend for the country is almost similar as that of Northern Europe. While life expectancy tend to be slightly lower for Singapore compared to Northern Europe before 1990, the trend lines from 1990 to 2010 overlap; life expectancy is, on average, 80 years for both Singapore and Northern Europe at present. In contrast, the South East Asia trend lags behind, with the gap closing over time. From 1965, life expectation for South East Asia was, on average, 50 years, and gains have been

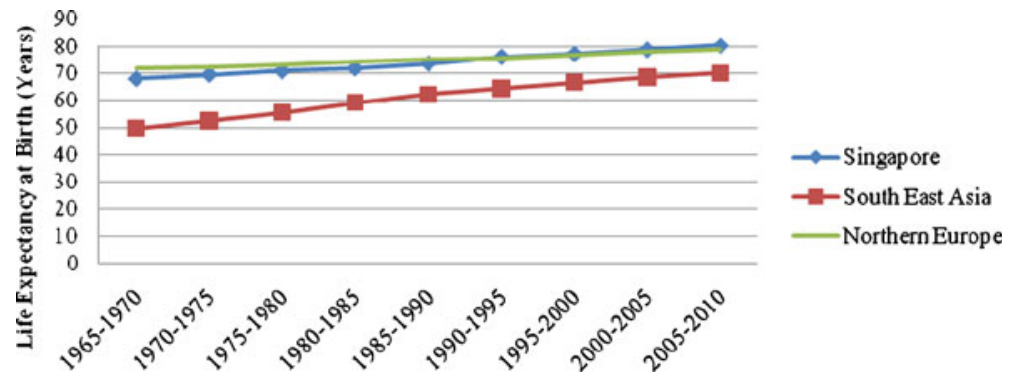

Source: Population Division, Department of Economic and Social Affairs of the United Nations Secretariat, World Population Prospects: The 2008 Revision

Fig. 1 Life expectancy, Singapore and selected regions, 1965-2010 (Population Division, Department of Economic and Social Affairs of the United Nations Secretariat, World Population Prospects: The 2008 Revision) 
steadily made over the decades, reaching an average of 70 years. What is clear then is that, within South East Asia, Singapore is an exception with similar life expectancy to Northern Europe.

Figures 2 and 3 disaggregate life expectancy at birth by sex for Singapore, South East Asia, and Northern Europe. In Fig. 2, female life expectancy in Singapore follows closely that of Northern Europe. While average life expectancy for females in Singapore was 70 years in 1965, the average for Northern Europe was slightly higher. By 1990, Singapore had caught up with Northern Europe. In both Singapore and Northern Europe, women are living longer, up to 80 years and over. Female life expectancy, on average, for South East Asia was 50 years in 1965, increasing to over 70 years in 2010 .

In Fig. 3, the average male life expectancy in Singapore, South East Asia, and Northern Europe is lower than that of the female. The levels, using the trend lines, are lower throughout 1965-2010. These figures show that men in Singapore and Northern Europe tend to live up to 80 years, but women from the same regions exceed this, living beyond 80 years at present.

There are various possible explanations for the relatively longer life expectation of females, particularly in gains made in the second half of the twentieth century. Risk factors to which males are exposed such as tobacco, alcohol and occupational hazards were cited as reasons for their higher mortality (Kinsella and Velkoff 2001). It is suggested that women tend to work in the home instead of joining the labor force, which would reduce exposure to these risk factors (Kinsella and Velkoff 2001). Precise explanations could not be drawn due to the recognized interplay of biological, social, behavioral, and environmental factors. The link between women's longer lives and their health status has serious implications. Health statistics showed that women suffer from chronic illnesses more than men, while the latter have a higher incidence of cardiovascular diseases (Muller et al. 1993). As a consequence, in many countries, older women often require physical assistance and care due to illnesses such as stroke, heart disease, and asthma. Longer life expectancy, chronic illnesses, and the lack of financial resources over the lifetime accentuate the health and social support needed by older women.

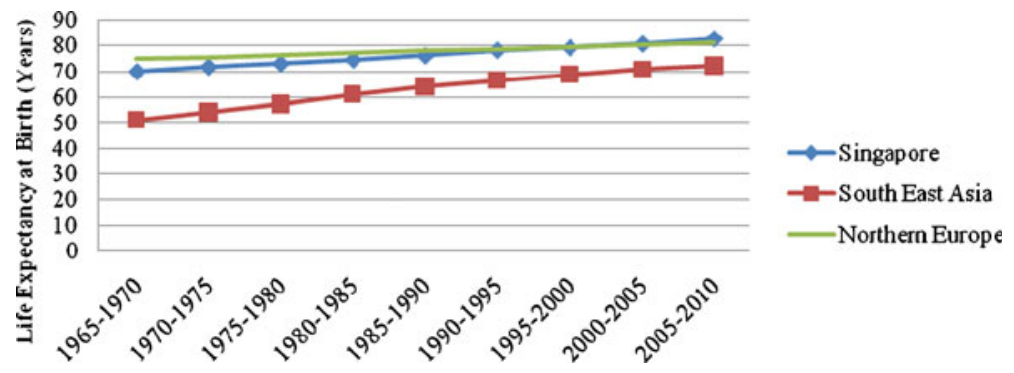

Source: Population Division, Department of Economic and Social Affairs of the United Nations Secretariat, World Population Prospects: The 2008 Revision

Fig. 2 Life expectancy at birth for females, Singapore and selected regions, 1965-2010 (Population Division, Department of Economic and Social Affairs of the United Nations Secretariat, World Population Prospects: The 2008 Revision) 




Fig. 3 Life expectancy at birth for males, Singapore and selected regions, 1965-2010 (Population Division, Department of Economic and Social Affairs of the United Nations Secretariat, World Population Prospects: The 2008 Revision)

\section{Health status}

Figure 4 provides information on the major health risks that Singaporean women face. These are, for non-communicable diseases, high levels of cholesterol, high blood pressure, and adult-onset diabetes prevalence (type 2). They contribute to the increased incidence of chronic illnesses in old age. These account for increased risks of heart disease, high blood pressure, and stroke. Diabetes can cause other serious complications such as blindness, kidney failure, and lower-extremity amputations. As can be seen in Fig. 4, the risks increase sharply as the women age, leading to eventual frailty. For cholesterol levels, there is a progressive rise from the age group 30-39, peaking at age group 50-59. The prevalence rises sharply for high blood pressure as women age from their thirties to their sixties. The prevalence of type- 2 diabetes rises at a similar rate to high blood pressure for women between the 30-39 and 40-49 age groups; the rate of increase is lower as women age out of the 40-49 age group, tapering off at the 60-69 age group.

\section{Old-age support ratios}

With the ideals of Confucian values and filial piety in Singaporean society, older people, both men and women, are expected to receive physical assistance and

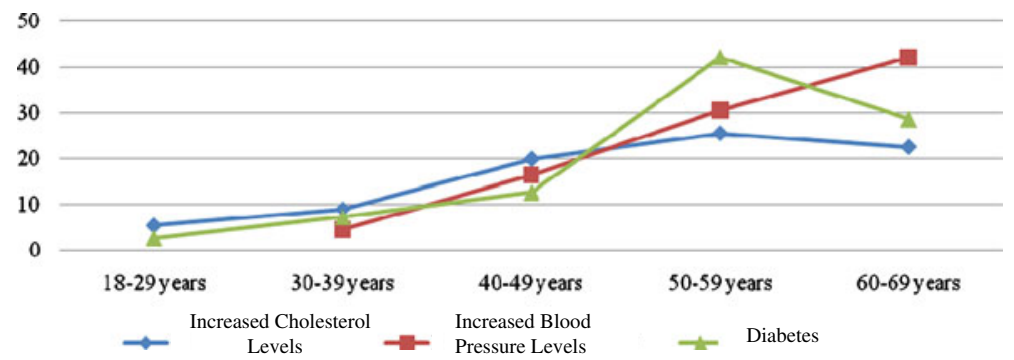

Source: World Health Organization and Singapore Ministry of Health National Health Survey 2004 Notes: The $Y$-axis consists of measures for the different non-communicable disease indicators

Fig. 4 Non-communicable disease indicators for women, by age group, Singapore, 2004 (World Health Organization and Singapore Ministry of Health National Health Survey 2004). The $Y$-axis consists of measures for the different non-communicable disease indicators 
care from their children. This happens through co-residence with children who will provide financial, health, and social assistance including companionship (Chan 2001). However, from a demographic perspective, the care and support from children may be less possible in the long term because there will be fewer children in the future. The trend shows that, since 1965, total fertility has fallen from 3.46 children per woman to 1.27 in 2010 (Population Division, UN DESA 2009). This issue of old-age dependency is exacerbated among older women who will live longer. The trends in old-age support ratios in Singapore, compared to South East Asia and Northern Europe, are presented in Fig. 5.

In Fig. 5, the old-age support ratio in Singapore and Southeast Asia is lower than in Northern Europe. Singapore and Southeast Asia have less population aged 15-64, compared to the elderly aged $65+$ and over. However, the trend is improving for Singapore from 1985 to 2010 since the number of 15 to 64-year-olds exceeds those 65 years and over. The increase in the productive age cohort 1564 years is attributed to labor migration from other countries. From the Confucian view, this does not bode well for the prospect of children supporting the older relatives.

The next section describes the economic and social policies of the country to meet the needs of the aging population and how state support is tied strongly to family support.

\section{Economic and social policies for older adults}

Given the aging population in Singapore, it is expected that individuals remain economically active for a longer period before retiring. It is not possible to speculate whether older adults choose to keep working because they enjoy work or because of the lack of income security. According to Statistics Singapore 2005 , from a total number of 1.7 million economically active population, 32,400 $(1.8 \%)$ were aged 65 years and above. Within this sub-group, 26 percent were women. An economically active population includes individuals who have reached the statutory minimum age of retirement which is 62 years but continue

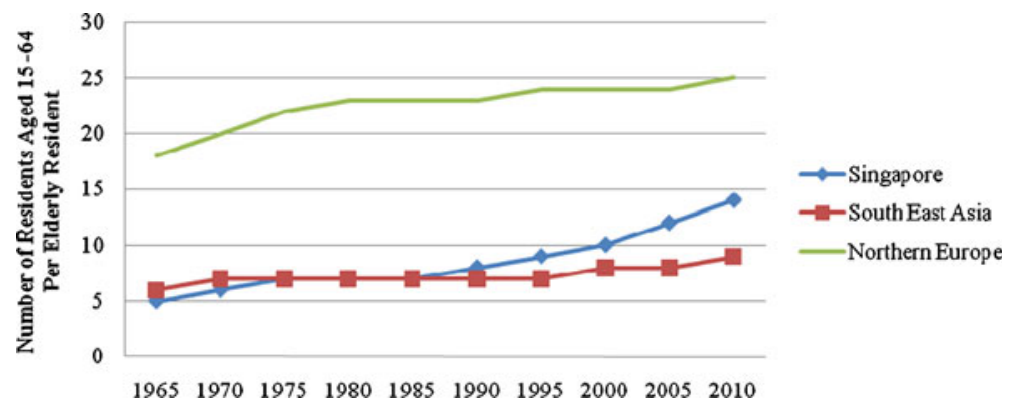

Source: Population Division, Department of Economic and Social Affairs of the United Nations Secretariat, World Population Prospects: The 2008 Revision

Fig. 5 Old age support ratio, Singapore and selected regions, 1965-2010 (Population Division, Department of Economic and Social Affairs of the United Nations Secretariat, World Population Prospects: The 2008 Revision) 
to work for income. Based on the National Employment Act, employers are allowed to retain employees beyond age 62. There is no legislated compulsory retirement age.

The assessment of economic and social policies, using only the economically active aged 65 years and above, will provide a clear indication of how well designed and targeted these policies are for the aging population in Singapore. The economic and social status of the economically inactive elderly will be more difficult to assess as there are fewer policies that target them directly on the basis of their age. Data for policymaking are less available for the economically inactive old whose information is not well documented.

The propensity for older adults to be economically active is reflected in the social security fund, the Central Provident Fund (CPF) for private-sector employees (Social Security Programs throughout the World: Asia and the Pacific 2008). ${ }^{3}$ In the CPF, employers and employees alike in the private sector continue to make mandatory contributions for those employees aged more than 65. When the CPF was introduced by the British Colonial Administration in 1955, the aim was to provide full financial support to meet the old-age needs of workers when they retire at age 55 . The bases of this fund were to ensure that: (a) workers would be self-reliant in their old age through their CPF savings, (b) workers from the colonies would not be a financial burden to the British Empire, and (c) there would be no need for redistribution and social welfare in Singapore (Pai, World Bank 2006). In contrast, Northern Europe social security provides old-age financial support upon reaching pensionable age, which is funded from government general revenues as well as some employer and employee contributions (Social Security Programs throughout the World: Europe 2010).

In the case of the Singapore CPF, as with other provident funds introduced in former British colonies, longer life expectancy and the increase in the proportion of older adults in the population were not taken into consideration in the design. Figure 6 shows the rates of mandatory CPF contributions for employers and employees by age group which decline with the aging progression. These rates pertain to employees who earn at least SGD \$1,500 a month. The sharpest decline occurs when the employee moves from the 50-55 group to the 55-60 group. In comparing employer and employee contributions, the decline is sharper for employers. The rationale for this among workers 55 years and above is to make it more attractive for employers to hire older workers.

From Fig. 6, when an employee is older than 65 and has more health and social support requirements, the amount of financial support from CPF may not be sufficient. This will have serious implications among older women living longer than older men. They have to depend more on different types of resources apart from CPF such as family and community support.

CPF savings can be withdrawn by individual members for various purposes, including retirement and health care. For retirement, CPF members at age 55 establish a retirement account where they must place a maximum of SGD $\$ 106,000$ (up to $50 \%$ of which can be pledged property and the remainder, in cash). The cash proportion ensures monthly income from age 62, until the

\footnotetext{
${ }^{3} \mathrm{CPF}$ and private-sector employment is the main focus as private-sector employees make up $97 \%$ of the labor force, while public-sector employees make up only $3 \%$ of the labor force in Singapore
} 


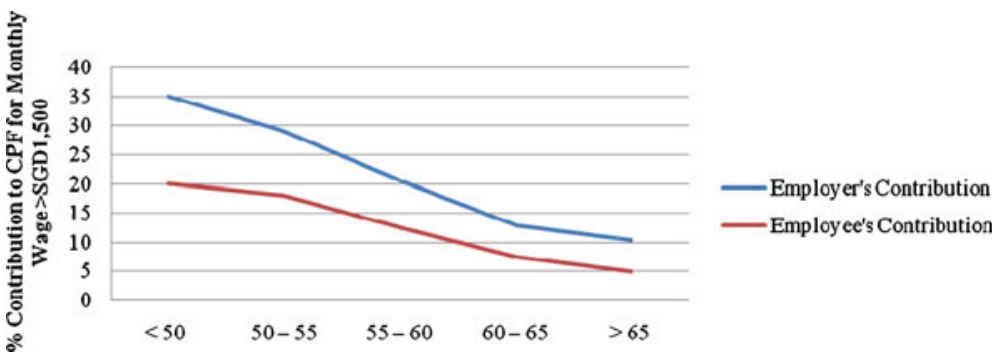

Source: Central Provident Fund, Employer's Guide to CPF www.cpf.gov.sg

Fig. 6 Percentage of employers' and employees' mandatory CPF contributions by employees' age group, Singapore (Central Provident Fund, Employer's Guide to CPF)

account is depleted. For health care, CPF members are required to set aside a minimum of SGD $\$ 34,500$ of their total CPF savings in their Medisave account to meet their hospitalization expenses after the statutory retirement age of 62. If an older adult does not have sufficient savings to pay for hospitalization expenses, the adult child who is a CPF member can pay for the older parent's expenses.

Under the Eldershield program component of CPF, members' basic out-of-pocket expenses are covered if they are unable to carry out at least three of six activities of daily living (ADLs): washing, dressing, feeding, going to the toilet, mobility and transferring. Annual premiums paid to the Eldershield program can be in cash or deducted from the member's Medisave savings. As in the case of Medisave, an adult child can pay for his / her older parent's out-of-pocket expenses covering physical assistance and care needs if the latter is unable to make the Eldershield premium payments. The Eldershield monthly cash payout is SGD \$400 for a maximum period of 6 years. The minimum amount required for health-care savings in $\mathrm{CPF}$ and the cash payments for individuals with limited ADLs are not different for older men and women. This holds despite the longer life expectancy of women with their predisposition to chronic illnesses for a longer period.

\section{Socio-economic status of older women}

To determine whether the coverage of these economic and social policies for older women minimizes vulnerability and ensures the affordability of health and social needs, their socio-economic status is examined.

\section{Educational attainment}

A better understanding of whether economically active older women 65 years and above are financially secure can be gained by examining the highest level of education they attained. Given the structure of the modern economy in Singapore, a worker who has a higher level of education is more likely to earn a higher income and achieve job security. However, the current generation of economically active older women is arguably far less competitive than their younger counterparts due to 
Table 1 Percentage distribution of women aged 65 and above by highest educational attainment, Singapore, 2005

\begin{tabular}{lr} 
Educational level & Percentage \\
\hline No formal education & 64.0 \\
Primary level & 11.0 \\
Lower secondary level & 7.3 \\
Secondary level & 7.0 \\
Upper secondary level & 4.6 \\
Polytechnic & 0.3 \\
Other diploma & 1.6 \\
University & 4.2 \\
Total & 100.0
\end{tabular}

Statistics Singapore, General Household Survey 2005

lower education. A woman aged 65 would have been born at the end of the Japanese Occupation in World War II. If educational opportunity was available, she would have achieved an upper secondary education by the time of Singapore's independence in 1965. This is not the case, though. Table 1 shows that 64 percent of women aged 65 and above and who are still economically active have no formal education. The proportion of older women with less than formal education at the secondary level is higher than that of older men within the same age group. Assuming that the older women are the main income earners in the household, this strongly implies that they earn lower incomes than their younger and better educated counterparts as well as males in their same age group. The assumption that the older women are the breadwinners in the household is not unreasonable since about four in ten in this age group are widowed (National Survey of Senior Citizens 2005).

Occupational status

Table 2 shows the occupational status of economically active women 65 years and over in 2005. The highest percentage was found among employees. This bodes well since they are eligible for CPF social security coverage. However, the

Table 2 Percentage distribution of women aged 65 and above by occupational status, Singapore, 2005

\begin{tabular}{lr}
\hline Occupational status & Percentage \\
\hline Employer & 10.5 \\
Own account worker & 12.0 \\
Employee & 72.6 \\
Unpaid family worker & 4.9 \\
Total & 100.0
\end{tabular}

Statistics Singapore, General Household Survey 2005 
small percentage of older women who are unpaid family workers $(4.9 \%)$ face increased vulnerability as they only receive in-kind transfers from the family in exchange for work. They are, then, entirely dependent on the family for their welfare.

\section{Income security}

Given data from the Statistics Singapore Household Expenditure Survey (HES) 2007/08, older adults, both men and women aged 65 and above, earned an average monthly income of SGD $\$ 1,082$. However, there is no information available on its standard deviation. Statistics are available for the main income earner (regardless of household size) and by the Housing Development Board (HDB) housing ownership. Public housing ownership is included in the statistics because Singaporean citizens have the inalienable right to housing where housing policy acts as a redistribution mechanism. Over 90 percent of housing ownership in Singapore is public (HDB). Housing policy compensates for the social security design. In contrast, among older adults aged 65 and above with private housing ownership, the average monthly income was substantially higher at $\$ 5,965$. It would be important to examine their income distribution. Using HES 2007/08, Fig. 7 shows the population income distribution by age group and ownership of public housing or private homes. There are no data available on the income distribution by sex.

From this figure, it can be seen that older adults have average incomes that are lower than those of younger people. Earnings peak in the range of 3560 years which is when labor productivity is highest. Average incomes are lower by age among individuals who own public homes compared to those who own private homes. However, it is likely that it is not only age that drives earnings capability. The lower level of education and skills of an older person are likely to yield lower earnings, compared to the higher education and skills of a younger counterpart. To assess the effect of lower income on security, the average expenditures of older adults are assessed to determine if they have sufficient income to meet their needs and still have savings.

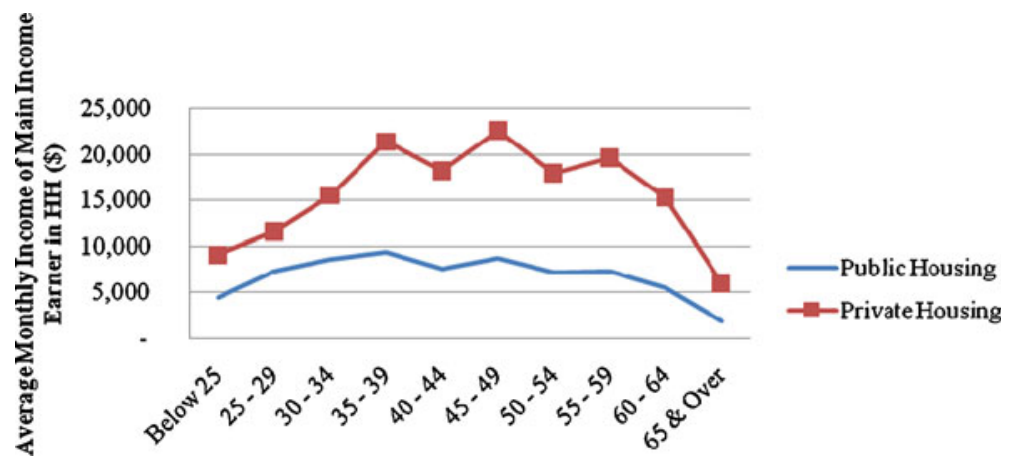

Source: Statistics Singapore Housing Expenditure Survey 2007/08

Fig. 7 Average monthly income by age group and housing ownership, Singapore, 2008 (Statistics Singapore Housing Expenditure Survey 2007/08) 
From the Statistics Singapore Household Expenditure Survey (HES) 2007/ 08 , adults aged 65 and above in public housing incurred an average monthly expenditure of SGD $\$ 1,601$. Expenditures exceeded the average earned monthly income of $\$ 1,082$. They failed to achieve income sufficiency and were unable to save.

Adults aged 65 and above in private housing have an average monthly expenditure of SGD $\$ 3,946$. In comparison with adults 65 years and over in public housing, those in private housing with average monthly incomes of SGD $\$ 5,965$ were comfortably able to achieve income sufficiency and save. Hence, older adults aged 65 and over with an average monthly income of SGD \$1,082 in public housing are a vulnerable group since they are unable to achieve the desired income security. When queried on why their income was perceived to be insufficient, reasons cited in the National Survey of Senior Citizens (2005) were the high cost of living, low income, and high medical costs.

Figure 8 presents the expenditure distribution by age group and housing ownership. Average expenditures were lower throughout the age of individuals who own public housing compared to those who own private housing. For owners of public housing, expenditures tended to rise slightly for the age group 25-29, peaking at age group 55-59. From age 60 onwards, a decline occured. For owners of private housing, the pattern was different. Expenditures tended to plateau from ages 25-29 until 55-59 and decline thereafter. The expenditure gap between public and private homeowners is notable. There is, then, a decline in expenditures from age 60 onwards, but the rate is sharper for owners of public housing. However, the rate of spending is lower for private homeowners. The implications of this are that, even though all older adults regardless of type of housing ownership upon turning 60 begin to reduce their spending, the people in public housing will not have sufficient resources to meet their expenses. Consequently, older adults in public housing are forced to depend more on their family for support as can be seen in CPF social security policy. The future looks bleak for old age dependence on the family since there are fewer children.

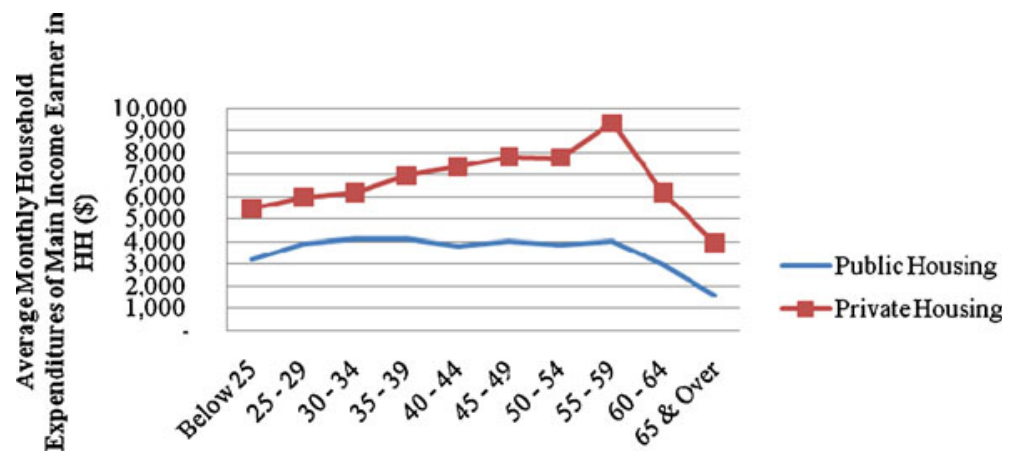

Source: Statistics Singapore Housing Expenditure Survey 2007/08

Fig. 8 Average monthly expenditure by age group and housing ownership, Singapore, 2008 (Statistics Singapore Housing Expenditure Survey 2007/08) 
Children as old age income support and care providers

Older persons' dependence on children for assistance particularly in terms of finances is reinforced by the findings from the National Survey for Senior Citizens (2005). Nearly half (44.7\%) of the survey respondents aged 55 and above cited their children as the most important source of financial support. Older women are more dependent on their children for income support than older men. The survey shows that 77.3 percent of the older women respondents were more likely to rely on their children compared to 54.0 percent of the older men respondents. Older women were less likely to work, and those who worked had lower earnings. As such, later in life, they have less savings or fewer sources of income.

Figure 9 presents the different financial sources that older women tap. Based on the data from the National Population Census (2000), overwhelmingly, older women relied on allowances given by children. Smaller amounts were drawn from the spouse or from income and savings. However, the amount of financial assistance received from children declined as women reached 70 and beyond. Allowances began to rise again after age 75 . This may be due to higher expenditures on longterm care in old age.

The pattern from Fig. 9 when related with the older women's occupational status in Table 2 implies that even if an older woman was a paid employee, the wages would still be not sufficient, and she would need allowances from her children. According to National Survey for Senior Citizens (2005), the number of children as the most important source of income dependence increases with age starting at 31.9 percent among respondents aged 55-64 to 55.8\% among those aged 65-74 and 63.7 percent among respondents aged 75 and above. Increased reliance on children with age is exacerbated for older women because of longer life expectancy.

To examine other types of support received from children such as physical assistance and care in old age, Table 3 provides information on multiple generations' co-residence by male and female. These summary statistics provide a snapshot of whether more females or males tend to reside with their children which then increases the likelihood of receiving care and support (Chan 1997, 1999).



Source: Statistics Singapore, National Population Census 2000

Fig. 9 Different financial sources of older women, Singapore, 2000 (Statistics Singapore, National Population Census 2000) 
Table 3 Household structure (number of persons per household) by sex of the widowed elderly by sex, Singapore, 2005

\begin{tabular}{|c|c|c|c|c|}
\hline & Male & & Female & \\
\hline \multicolumn{5}{|l|}{ No family nucleus } \\
\hline One person & 2,765 & 68.6 & 9,656 & 67.1 \\
\hline \multirow[t]{2}{*}{ Two or more persons } & 1,261 & 31.4 & 4,732 & 32.9 \\
\hline & $4,026(21.9)$ & 100.0 & $14,388(78.1)$ & 100.0 \\
\hline \multicolumn{5}{|l|}{ One family nucleus } \\
\hline One generation & - & - & 15 & .05 \\
\hline Two generations & 6,426 & 86.4 & 28,675 & 89.0 \\
\hline \multirow[t]{2}{*}{ Three or more generations } & 1,009 & 13.6 & 3,535 & 11.0 \\
\hline & $7,435(18.7)$ & 100.0 & $32,225(81.3)$ & 100.0 \\
\hline \multicolumn{5}{|l|}{ Two family nuclei } \\
\hline One generation & - & - & - & - \\
\hline Two generations & 172 & 34.8 & 822 & 30.4 \\
\hline \multirow[t]{2}{*}{ Three or more generations } & 322 & 65.2 & 1,885 & 69.6 \\
\hline & $494(15.4)$ & 100.0 & $2,707(84.6)$ & 100.0 \\
\hline \multicolumn{5}{|l|}{ Three or more family nuclei } \\
\hline One of two generations & - & - & 6 & 3.9 \\
\hline \multirow[t]{2}{*}{ Three or more generations } & 30 & 100.0 & 147 & 96.1 \\
\hline & $30(16.4)$ & 100.0 & $153(83.6)$ & 100.0 \\
\hline
\end{tabular}

Statistics Singapore, General Household Survey 2005

Given data limitations, Table 3 only provides statistics for widowed males and females. Assuming that men and women are widowed in old age, these statistics provide some description of older adults who were alone and those who moved in with their children and/or grandchildren. A majority of widowed women (89\%) and men $(86.4 \%)$ moved to co-reside with their adult children. Slightly more than a tenth $(11 \%)$ co-resided with their children and grandchildren or even great grandchildren. About 14 percent $(13.6 \%)$ of widowed older men co-resided with three or more generations.

As such, it can be summarized that older women's dependence on their children is similar to that of men and takes various forms. This consists of income support, children as the main source of financial assistance, and children as co-payers for health care, as provider of care, and co-residents.

\section{Conclusions}

A key demographic feature in Singapore is that women have longer years of life than men. Living beyond 80 years for Singaporean women is a human success story, and this paper has shown that they are on par with their Northern European counterparts. This parity has been achieved at a relatively short period of 45 years when Singapore progressed from a British colony to a high-income industrialized country. This is 
where the convergence between Singapore and Northern Europe ends. Older women in Singapore are less likely to live well and have a high quality of life, as their health status declines with age. This is because, historically, Singapore has not developed a responsive social welfare system similar to Northern Europe. This paper has shown that the current cohort of older Singaporean women aged 65 and above now have a lower socio-economic position later in life, exacerbated by lower social security. These women have no or little formal education; low level of occupational status; and limited social security protection as few worked outside of the home in the formal sector.

Given how economic and social policies have evolved in Singapore over time, older women tend to fall back on their children and not on their spouses for old-age support. Children's support is manifested in various ways-financial for out-ofpocket health care expenses, co-residence, and care giving. As there are fewer children in Singapore for the old to depend on, this situation may not be tenable in the long term.

Given their fragile economic and social circumstances, older women in Singapore are a vulnerable group as their health status declines with age. Optimistically, the future generations of women in Singapore who are better educated and have a higher occupational status will be able to better insulate themselves against the risks faced by women in old age.

Open Access This article is distributed under the terms of the Creative Commons Attribution Noncommercial License which permits any noncommercial use, distribution, and reproduction in any medium, provided the original author(s) and source are credited.

\section{References}

Central Provident Fund Board (2010) Central Provident Fund Board, employer's guide to CPF. At: www. cpf.gov.sg

Chan A (1997) An overview of living arrangements and social support exchanges of older Singaporeans. Asia Pac Popul J 12(4):35-50

Chan A (1999) The social and economic consequences of aging in Asia: an introduction. Asian J Soc Sci 27(2):1-8

Chan A (2001) Singapore's changing age structure and the policy implications for financial security, employment, living arrangements and health care. Asian Metacenter Research Paper Series no. 3

Kinsella K, Velkoff V (2001) An aging world. US Census Bureau, series P95/01-1

Metha KK (2002) National policies on aging and long term care in Singapore, a case of cautious wisdom? In Phillips D, Chan ACM (eds) Aging and long term care national policies in the Asia Pacific. Institute of South East Asian Studies ISEAS/International Development Research Center IDRC, Canada

Muller L et al (1993) Behavior change and compliance: keys to improving cardiovascular health. Workshop VI. AHA Prevention Conference III. Circulation 88:1406-1407

Pai Y (2006) Comparing individual retirement accounts in Asia: Singapore, Thailand, Hong Kong and PRC. The World Bank, Washington DC

Population Division, Department of Economic and Social Affairs of the United Nations Secretariat, World Population Prospects: The 2008 Revision

Singapore Ministry of Community Development, Youth and Sports (MCYS) (2005) National Survey for Senior Citizens, 2005.

Singapore Ministry of Community Development, Youth and Sports (MCYS) State of the elderly in Singapore 2008/2009: trends in population aging, profile of Singapore's elderly population (release 1). MCYS, Singapore 
Singapore Ministry of Health (MOH) "National Health Survey 2004". MOH, Singapore

Social Security Programs throughout the World: Asia and the Pacific 2008 www.socialsecuritypolicy.gov/ policy. Office of Retirement and Disability Policy, US Social Security Administration, Washington DC Social Security Programs throughout the World: Europe 2010 www.socialsecuritypolicy.gov/policy. Office of Retirement and Disability Policy, US Social Security Administration, Washington DC

Statistics Singapore "National Population Census 2000". National Statistical Authority, Singapore Statistics Singapore "General Household Survey 2005”. National Statistical Authority, Singapore Statistics Singapore "Housing Expenditure Survey 2007/08". National Statistical Authority, Singapore Statistics Singapore "National Population Census 2010". National Statistical Authority, Singapore 